\section{Consensus Value}

C. Vidal ${ }^{1}$ und W.-R. Külpmann ${ }^{2}$

${ }^{1}$ Landeskriminalamt Niedersachsen, Dezernat 53 „Chemie“, Hannover, Deutschland

${ }^{2}$ Hannover, Deutschland

\section{Synonym(e) Konsensuswert}

Englischer Begriff consensus value

Definition Teilnehmermittelwert.

Beschreibung Der Konsensuswert wird in manchen Ländern zur Bewertung von Ringversuchen verwendet. Er wird ermittelt, indem zunächst alle für die Bestimmung einer Messgröße mit einem bestimmten Verfahren eingegangenen
Messwerte gemittelt werden $(\overline{\mathrm{x}})$ und die Standardabweichung (s) errechnet wird. Werte außerhalb $\bar{x} \pm 3$ s werden anschließend als Ausreißer eliminiert. Der Konsensuswert ergibt sich als arithmetisches Mittel der verbliebenen Messwerte. Nachteile des Vorgehens:

- Grundsätzliche Mängel eines bestimmten Verfahrens werden nicht erkannt.

- Allgemeine Nachlässigkeiten bei der Handhabung der Proben werden toleriert (z. B. kein Lichtschutz bei $>$ Bilirubin-Bestimmung).

\section{Literatur}

Stamm D, Büttner J (1995) Klinisch-chemische Analytik. In: Greiling H, Gressner AM (Hrsg) Lehrbuch der klinischen Chemie und Pathobiochemie. Schattauer Verlag, Stuttgart, S 6-36 